\begin{tabular}{|c|c|}
\hline \multirow{3}{*}{ 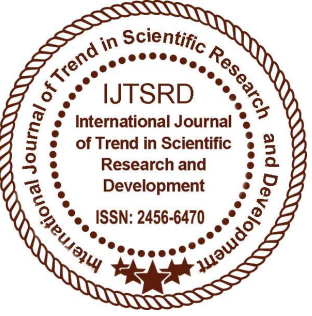 } & $\begin{array}{l}\text { International Journal of Trend in Scientific } \\
\text { Research and Development (IJTSRD) }\end{array}$ \\
\hline & UGC Approved International Open Access Journal \\
\hline & ISSN No: 2456 - 6470 | www.ijtsrd.com | Volume - 1 | Issue - 5 \\
\hline
\end{tabular}

\title{
A Comparative Study of Nutritional Status of Children Aged 11-14 Years of Low and High Economical Background, Surat
}

\author{
Dr. Bhavana Chauhan \\ S.M.Patel College Of HomeScience, \\ Vallabh Vidyanagar, Gujarat, India
}

\begin{abstract}
Nutritional status is the condition of health of an individual as influenced by nutrient intake and utilization in the body. Malnutrition is major public health problem in developing countries. Usually referred to as silent emergency, it has devastating effect on children, society and future humankind. The term malnutrition refers to both under nutrition as well as over-nutrition. Rural areas of developing countries are generally prioritized as regards nutrition intervention, because under nutrition is more widespread than in urban areas.
\end{abstract}

\section{OBJECTIVES OF THE STUDY}

$>$ To study the socio demographic profile of children from high and low socio economic groups in Surat.

$>$ To assess the nutritional status of children by anthropometry.

$>$ To study the biochemical.

$>$ To study the physical activity clinical sign and personal hygiene habits.

$>$ To correlate food intake with nutritional status.

\section{MATERIALS AND METHODS}

Comparative study is to assess the nutritional status of Shree Dayalji Karasanji Bhatarkar Vidyasankul's as 11-14 years old students of low economical background and Gajaraba Prathmik Shala's 11-14 years old students of high economical background. Total 100 children are included in the study of height, weight, BMI, family history; socio economical history, education and occupation of parents, monthly income, personal hygiene, clinical sign, puberty changes, dietary details, food frequency, questionnaire of child, activity patterns, meal frequency are recorded. Statistical analysis was conducted using SPSS I9 for mean, percentage, and test.

\section{RESULT}

The study concluded the nutritional status of government school children was poor than private school children. The prevalence of stunting and wasting was higher and low hemoglobin in government school. Hemoglobin percentage in private school $26 \%$ are normal and $\mathrm{n}$ government only $4 \%$ are normal while in private school $8 \%$ are highly anemic and $66 \%$ are in government school. There were $36 \%$ boys and $36 \%$ girls had BMI percentile $<25^{\text {th }}$ percentile in government school, while in private school $32 \%$ boys and $20 \%$ girls had BMI percentile $<25^{\text {th }}$ percentile.

KEYWORDS: Nutritional Status, School Going Children, Anthropometric Measurements, Haemoglobin, Body Mass Index, Socio Economic Background

\section{INTRODUCTION}

The foundation of good health and sound mind is laid during the school age period. A child's entire life determine by the food given to him during their childhood, because childhood period is of rapid growth and development. Poor personal hygiene in combination is related to nutritional deficiencies, worm infestation and diarrhea. It adversely affects 
the attendance of school and learning process in developing countries ${ }^{1}$, this rising epidemic along with the persistence of under nutrition and infectious typifies the 'double burden of malnutrition' (DBM) ${ }^{2}$ Proper nutrition, good personal hygiene helps in providing good health of children, \& it indirectly minimize the medical expenses of Indian government.

\section{Iron deficiency adversely affects}

$>$ the cognitive performance, behavior, and physical growth of infants, preschool and school-aged children;

$>$ the immune status and morbidity from infections of all age groups; and

$>$ The use of energy sources by muscles and thus the physical capacity and work performance of adolescents and adults of all age groups.

> Specifically, iron deficiency anemia during pregnancy

$>$ increases prenatal risks for mothers and neonates; and

$>$ Increases overall infant mortality.

From ages 11 through 14, a child develop in four main areas:

Physical development. Adolescence is a time of change throughout the body. A growth spurt usually occurs near the time of puberty. Girls begin to develop breasts and start their periods. Boys grow facial hair. Both boys and girls grow pubic hair. Boys may lag behind girls in height during these years, but they usually end up taller.

$>$ Cognitive development. This is how the brain develops the abilities to think, learn, reason, and remember. Kids this age typically focus on the present, but they are starting to understand that what they do now can have long-term effects. They are also beginning to see that issues are not just clear-cut and that information can be interpreted in different ways.

Emotional and social development. As they start to move from childhood into adulthood, adolescents feel the urge to be more independent from their families. Often, friends replace parents as a source of advice. When at home, adolescents may prefer spending time alone to being part of the family. Still, family support is important to help them build a strong sense of self.
Sensory and motor development. Kids this age may be a little awkward or clumsy. Their brains need time to adjust to longer limbs and bigger bodies. Getting regular moderate exercise can improve coordination and help your_child build healthy habits.

\section{MATERIAL AND METHOD}

The comparative study is done among the school students of 11-18 years by analyzing the blood samples to measure the concentration of haemoglobin (HB), to evaluate their Body Mass Index (BMI), dietary habits and the status of awareness regarding the food intake. It was project work for the partial fulfilment for the degree of Master's of Science in Dietetics and Food service Management.

The study included 100 school students aged 11-14 years of $6^{\text {th }}$ and $7^{\text {th }}$ standard from high and low socio-economical background, from two schools. Study is conducted both in male and female, to compare nutritional status and prevalence of amenia between these two groups. Before collecting data, I have taken written consent from participants and their parents. Participants who were not interested to provide data were excluded from the study and another volunteer was selected.

\section{DATA COLLECTION}

We were the team of me, one laboratory technicians and volunteer teachers from school, collected data and using a pretested questionnaire and measured hemoglobin concentration, height and weight of each student. Questionnaire gave us information of height, weight, BMI, family history, socio economical history, education and occupation of parents, monthly income, personal hygiene, clinical sign, puberty changes, dietary details, food frequency, questionnaire of child, activity patterns, meal frequency are recorded.

HB concentration was estimated as per Cyanmethaermoglobin method ${ }^{3}$ with the autochem 2011. Anemia was classified into three degree according to WHO; mild, moderate and severe. ${ }^{4}$ The procedure followed in checking the hemoglobin is as follows. $5 \mathrm{ml}$ of Drabkins reagent and that add to 20 micro $\mathrm{ml}$ of blood. Mix well and allow standing at room temperature for 5 Minutes completion for reaction. The color formed is then compared with 
International Journal of Trend in Scientific Research and Development (IJTSRD) ISSN: 2456-6470 the standard and reagent in a calorimeter at 540 nanometer.

Hemoglobin Concentration $=\frac{\text { optical density of test }}{\text { optical density of standard }} \times 15$

(Given per deciliter)

\section{RESULTS}

\begin{tabular}{|c|c|c|c|c|c|}
\hline \multicolumn{2}{|c|}{ PREVALENCE OF ANAEMIA IN CHILDREN BASED ON HAEMOGLOBIN ESTIMATION } \\
\hline Sr. No. & HB \% $\mathbf{( g m / d )}$ & \multicolumn{2}{|c|}{ School - 1 (Private) } & \multicolumn{2}{c|}{ School - 2 (Government) } \\
\hline & & $\mathrm{N}$ & Mean (HB) & $\mathrm{N}$ & Mean (HB) \\
\hline $\mathbf{1}$ & $>12.0$ & 27 & $12.75 \pm 0.24$ & 1 & $12.1 \pm 0.746$ \\
\hline $\mathbf{2}$ & $11.0-11.9$ & 12 & $11.36 \pm 0.14$ & 5 & $11.12 \pm 0.48$ \\
\hline $\mathbf{3}$ & $10.0-10.9$ & 7 & $10.40 \pm 0.134$ & 14 & $10.35 \pm 0.247$ \\
\hline $\mathbf{4}$ & $<10.0$ & 4 & $9.366 \pm 0.40$ & 30 & $9.06 \pm 0.88$ \\
\hline & Total & $\mathbf{5 0}$ & & $\mathbf{5 0}$ & \\
\hline
\end{tabular}

\section{HEMOGLOBIN ESTIMATION OF HIGH SOCIO- ECONOMICALBACKGROUND CHILDREN}

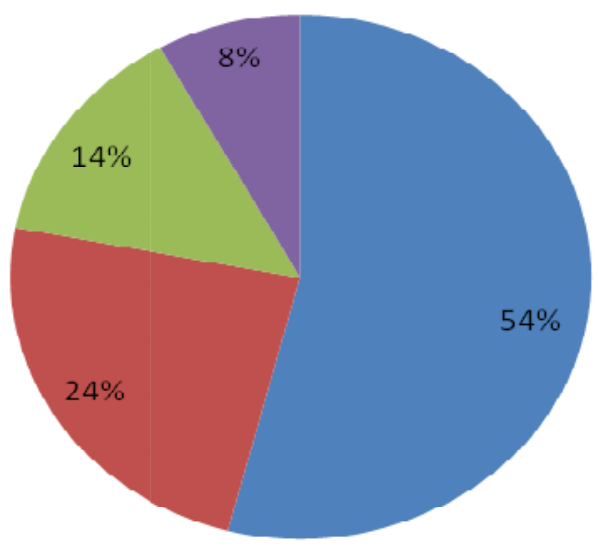

- $>=12.0$

- 11.0-11.9

10.0-10.9

- $<10.0$ 


\section{HEMOGLOBIN ESTIMATION OF LOW SOCIO- ECONOMICAL BACKGROUND CHILDREN}

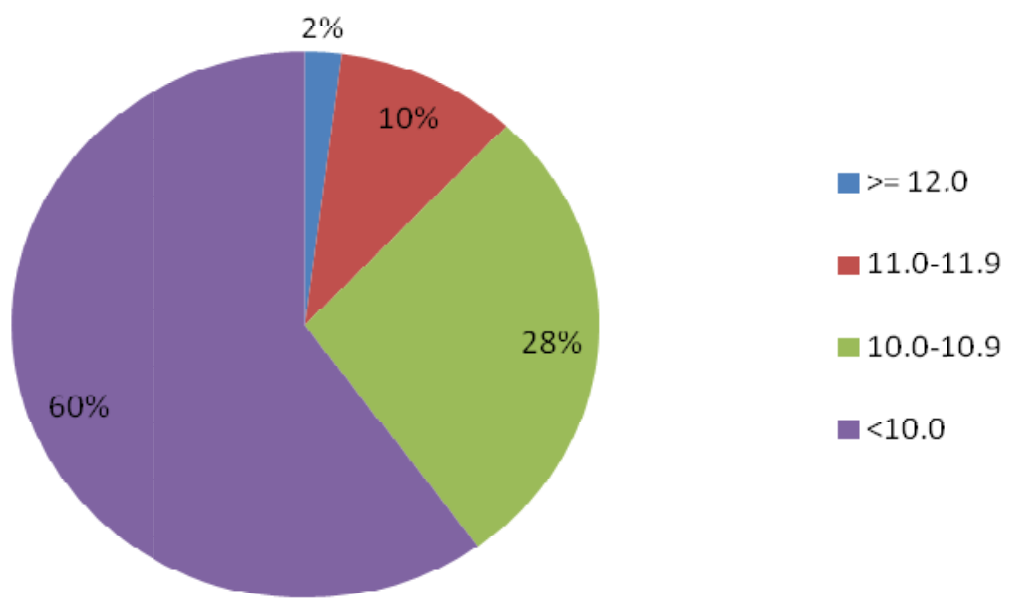

\section{CONCLUSION}

In high socio-economical background school's children, $54 \%$ of the students have haemoglobin concentration $>=12.0 \mathrm{gm} / \mathrm{dl}$, where as $8 \%$ are $<10.0$ $\mathrm{gm} / \mathrm{dl}$.

On other hand, in low socio-economical background school's children, $2 \%$ of the students have haemoglobin concentration $>=12.0 \mathrm{gm} / \mathrm{dl}$, where as $60 \%$ are $<10.0 \mathrm{gm} / \mathrm{dl}$. which is totally opposite of the children belonging to high socio-economical background school.

Result of the study revealed that the prevalence for stunting and wanting was more among children of government school than private school. The lower anthropometric measurements of Government school children can be attributed to their frequent illness due to lack of hygiene, which is reflected by the poor socio-economic status.

\section{REFERENCES}

1) Casapia M, Joseph SA, Nunez C, Rahme E, and Gyorkos TW: Parasite risk factors for stunting in grade 5 students in a community of extreme poverty in Peru. Int J Parasitol 2006, 36(7):741747.

2) Pollitt E: Early iron deficiency anemia and later mental retardation. Am J Clin Nutr 1999, 69(1):45.
3) Church, A. T. and Katigback, M. S. 1991, Home environment, nutritional status and maternal intelligence as determinants of intellectual development in rural Philippine children. Intelligence, 15: 49-78.

4) ICMR Nutrient Requirements and Recommended Dietary Allowances for Indian. A Report of the Expert Group of the Indian Council of Medical Research, New Delhi, India. (2008)

5) World Health Organization, 2009. 